\title{
Investigation into the Flammability Properties of Honeycomb Composites
}

Marc R. Nyden and James E. Brown

Building and Fire Research Laboratory

Gaithersburg, Maryland 20899

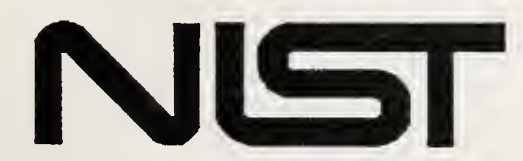

\section{United States Department of Commerce}

$\mathrm{QC}$ igy Administration

100 Institute of Standards and Technology

.456

№. 5509 

NISTIR 5509

\section{Investigation into the Flammability Properties of Honeycomb Composites}

Marc R. Nyden and James E. Brown

October, 1994

Building and Fire Research Laboratory

National Institute of Standards and Technology

Gaithersburg, MD 20899

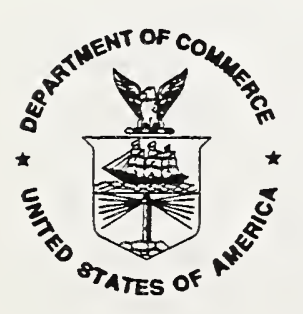

U.S. Department of Commerce

Ronald H. Brown, Secretary

Technology Administration

Mary L. Good, Under Secretary for Technology

National Institute of Standards and Technology

Arati Prabhakar, Director 



\title{
Investigation into the Flammability Properties of Honeycomb Composites
}

\author{
Marc R. Nyden and James E. Brown \\ Building and Fire Research Laboratory \\ National Institute of Standards and Technology \\ Gaithersburg, MD 20899
}

\begin{abstract}
The study which is the subject of this report was carried out in two stages. The objective of the first phase was to investigate the effect of electron beam irradiation and grafting on polymer flammability. The time to ignition and the rate-of-heat-release were measured for the combustion of a series of samples in which a fire resistant polymer was used to protect the surface of a more flammable polymer. The flammability properties of honeycomb composite materials, which are currently used in the interior cabin compartments of commercial aircraft, were examined in the second phase of this project. Analyses of the gases evolved during the thermal degradation of the components indicated that the phenol-formaldehyde resin makes a significant contribution to the flammability of these composites. The possibility that a more fire resistant formulation could be developed was examined by testing a series of resins which differed in the relative amounts of phenol and formaldehyde used in the reaction mixtures. The flammabilities of resins synthesized in excess phenol were measurably less than those synthesized in excess formaldehyde.
\end{abstract}

\section{BACKGROUND}

Synthetic polymers comprise a significant fraction of the fire load borne by commercial aircraft interiors. The flammability, smoke and toxicity characteristics of these materials may impact passenger survivability in the event of an in-flight or postcrash fire. In recent years, the FAA has issued improved fire test standards for aircraft seat cushions, panels (sidewalls, ceilings, stowage bins and partitions), cargo liners and evacuation slides. Demonstration tests and accident analysis indicate that these new standards enhance aircraft fire safety.

The Aviation Safety Research Act of 1988 (Public Law 001-591), gave the FAA the mandate and the responsibility for conducting long-range research to provide for decreases in the loss of life in air crashes, and specifically required the development of improved "fire and smoke resistant materials for aircraft interiors." It will, however, be necessary to develop a new generation of ultra-fire resistant polymeric materials to meet the goal of an "all-fire resistant aircraft cabin interior."

\section{INTRODUCTION}

The burning of most polymers may be viewed from the perspective of a simple model whereby volatile hydrocarbons, which are formed during the thermal degradation of the condensed phase, are combusted in the gas phase. The basis of this model is the hypothesis that all of the available oxygen is depleted in the flames above the surface of the solid. The cycle must be initiated by heat supplied from an external source, but it is self-sustaining as long as sufficient energy is generated and transferred to the surface of the polymer to further degrade it into fuel. The size of the fire is measured by the net rate-of-heat release (rhr) during this process.

In previous studies, molecular dynamics modeling was used to identify factors which contribute to the flammability of polymeric materials [1-5]. This research focussed on the mechanistic aspects of char formation during thermal degradation. Charring increases the fraction of the fuel retained in the condensed phase so that less combustible gases are evolved [6]. The presence of a surface char also 


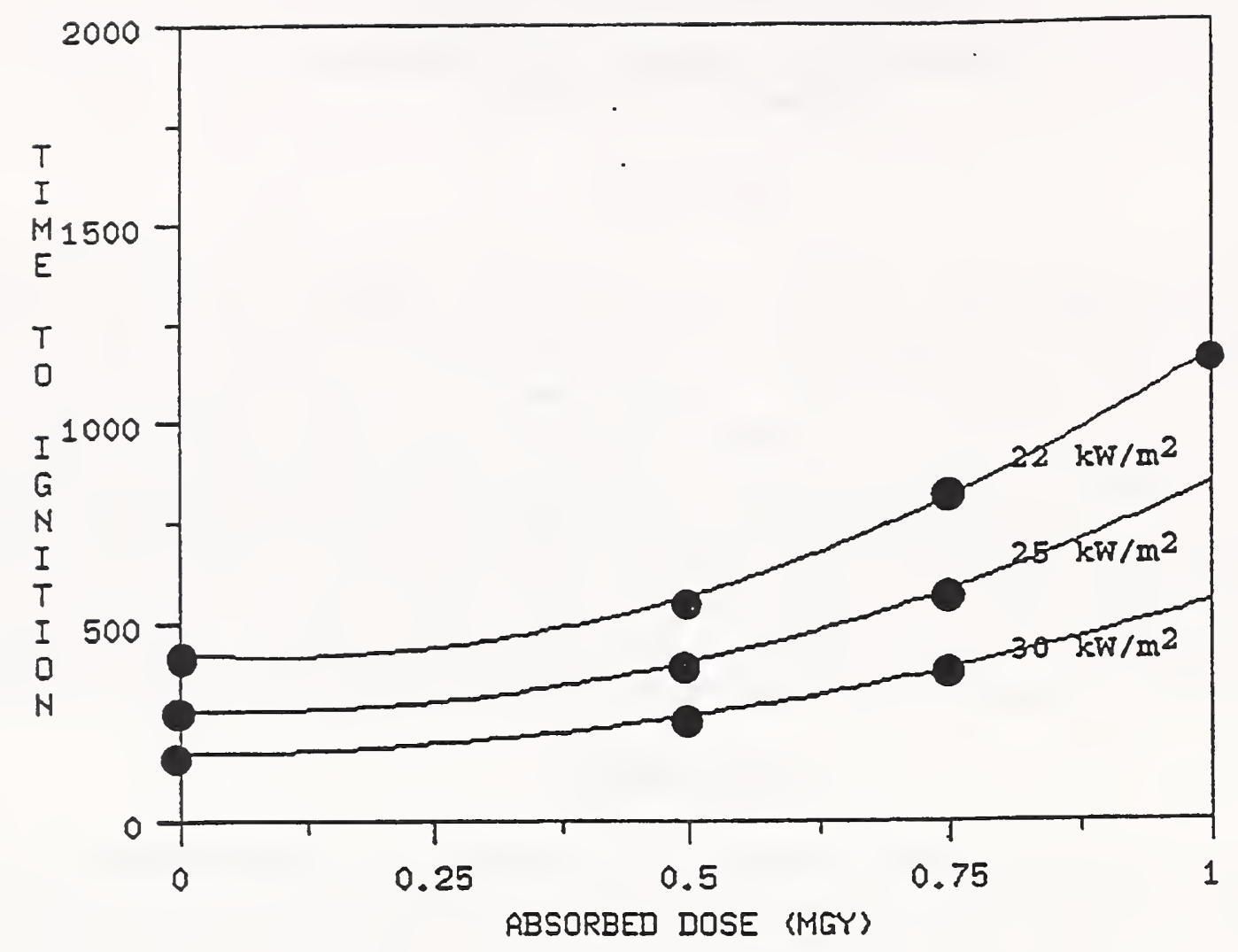

Figure 1. Times to ignition for electron beam irradiated PE as a function of absorbed dose.

insulates the unburnt polymer from the external heat source and obstructs the outward flow of combustible products from the degradation of the interior. Computer movies based on molecular dynamics simulations indicate that crosslinked polymers tend to undergo further crosslinking when burned, eventually forming high molecular weight, thermally stable chars. This prediction has been confirmed in Cone Calorimeter flammability measurements made on both radiation and chemically crosslinked polymers [1].

The presence of a source of oxygen within the condensed phase polymer can also have a favorable effect on flammability because less heat is released during burning if the material has already been partially oxidized. Furthermore, the oxidation reactions which are responsible for the heat release are much faster when they occur in the gas phase so that the rhr will be reduced in proportion to the fraction of hydrocarbon which is oxidized in the condensed phase. The processes involved in the condensed phase oxidation of the polymer, particularly the abstraction of $\mathrm{H}$ atoms, also promote the formation of char by creating free-radical sites where crosslinking reactions can occur.

The study which is the subject of this report was carried out in two stages. The objective of the first 
phase of this project was to investigate the effect of electron beam irradiation and grafting on polymer flammability. The flammability of a honeycomb composite material used in the sidewalls, ceilings and stowage bins of commercial aircraft was measured on the Cone Calorimeter as a function of the dose of radiation absorbed by the sample. The feasibility of using fire resistant grafts to reduce the flammability of aircraft materials was also explored by measuring the time to ignition and rhr of a series of polystyrene composites. In the second phase of this project, the contribution of the phenol-formaldehyde (PF) resin to the overall flammability of honeycomb composite material was determined and more fire resistant formulations were developed.

\section{EXPERIMENTAL}

\section{A. Polyethylene}

PE $\left(M_{w}=125000\right.$ from Scientific Polymer Products $\left.{ }^{a}\right)$ was melt pressed into disks (about $6 \mathrm{~cm}$ in diameter and $1 \mathrm{~cm}$ thick) and irradiated in a $\mathrm{N}_{2}$ atmosphere with $1 \mathrm{Mev}$ electrons from a Van der Graaf accelerator. The density of crosslinks, as determined by solvent swelling in xylene, was obtained as a function of depth for a disk which had received an overall dose of $0.5 \mathrm{MGy}$. The frequency ranged from about 1 crosslink for every 40 monomers at the surface to about 1 for every 900 monomers at the bottom of the disk.

\section{B. Polystyrene Composites}

A series of samples in which a fire resistant polymer was used to protect the surface of a fire prone polymer were prepared. Polystyrene (PS) (Aldrich) was chosen as the fire prone polymer because it is a well-characterized, high volume plastic with very poor flamm ability characteristics. Styrene-acrylonitrile (PSAN) copolymer (70\% styrene, 30\% acrylonitrile), obtained from Scientific Polymer Products, and acrylonitrile-vinylidine chloride (P-(AN-VDC)) copolymer ( $80 \%$ vinylidine chloride, $20 \%$ acrylonitrile), obtained from Polysciences, were selected as the fire resistant polymers. Samples were made either by melt pressing the fire resistant polymer on the surface of the PS (layered polymers), by coprecipitating the polymers from a common solvent (tetrahydrofuran), or by synthesizing a surface interpenetrating polymer network on the PS (grafted).

\section{Honeycomb Composites}

A composite material consisting of nomex honeycomb, fiber backing, and phenol-formaldehyde resin was obtained from the Federal Aviation Administration Technical Center. This material was identified by the code TP4/92. The original square panels were cut into circular disks with an outer diameter of $7.5 \mathrm{~cm}$ which was deemed most suitable for the Cone Calorimeter flammability measurements.

\section{Synthetic PF Resins}

The method used in synthesizing the PF resins is described in detail in reference 7. Reaction mixtures consisting of $0.5,1.0$ and 2.0 moles of formaldehyde (37\% solution, ASC Reagent, Sigma) per mole of

${ }^{a}$ Certain commercial equipment, instruments, or materials are identified in this paper in order to specify the experimental procedure. Such identification does not imply that the material or equipment identified is necessarily the best available for the purpose. 
phenol (ASC Reagent, Sigma) were refluxed in $15 \mathrm{ml}$ of $5 \mathrm{~N} \mathrm{NaOH}$ (ASC Reagent, Fisher) at $130{ }^{\circ} \mathrm{C}$ for approximately 2 hours. The prepolymer was washed in $\mathrm{H}_{2} \mathrm{O}$ to remove excess salts and dehydrated by heating at $100{ }^{\circ} \mathrm{C}$. Most of the samples were cured in air at $150{ }^{\circ} \mathrm{C}$ for 72 hours. In some cases, the resins were synthesized and cured in a $\mathrm{N}_{2}$ atmosphere. This precaution, however, did not have an obvious effect on the distribution of products observed during thermal degradation.

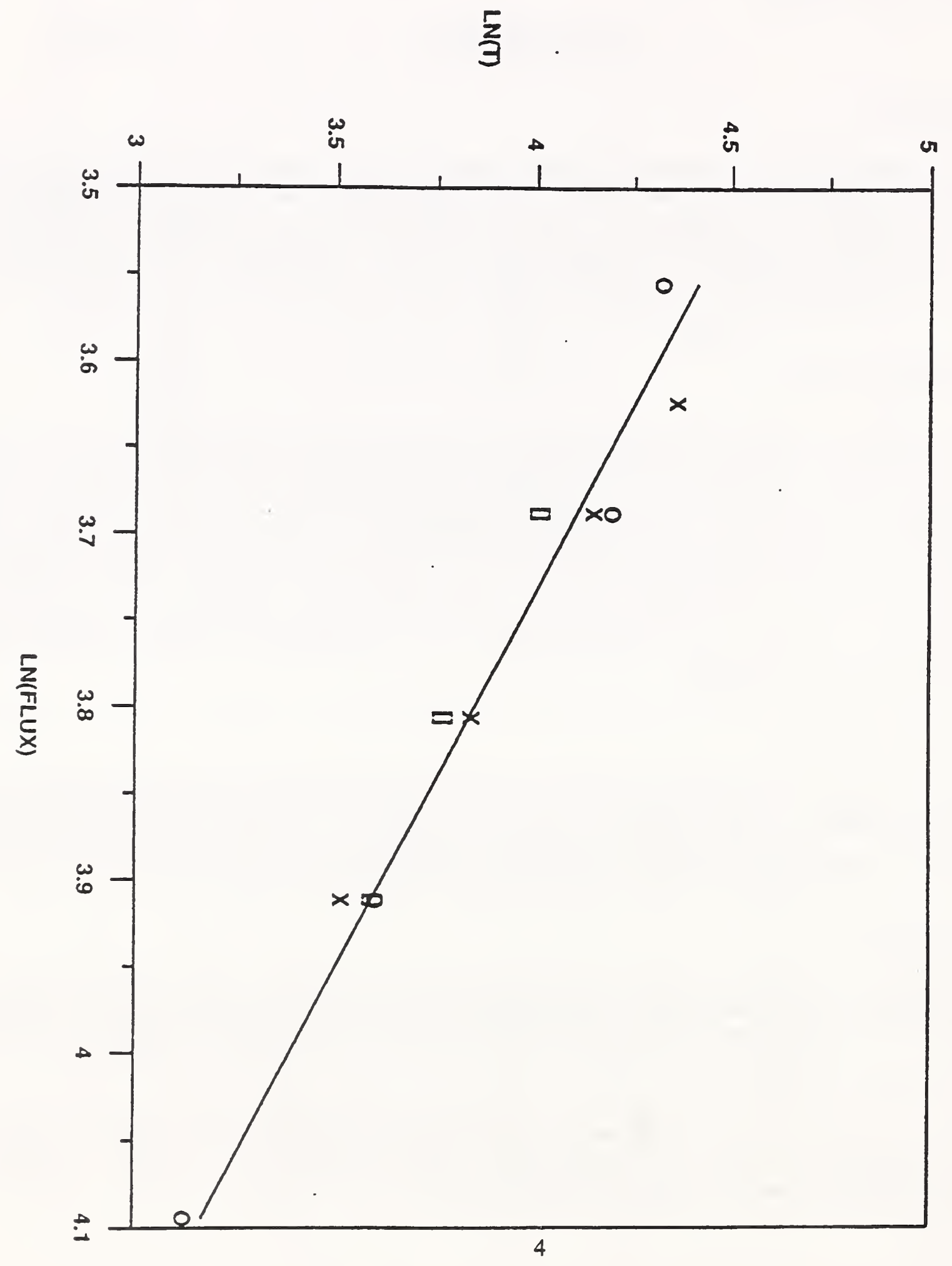

Figure 2. Ignition times corresponding to doses of $0(\mathrm{O}), 1.0(\mathrm{X})$ and $1.5([]) \mathrm{MGy}$. 

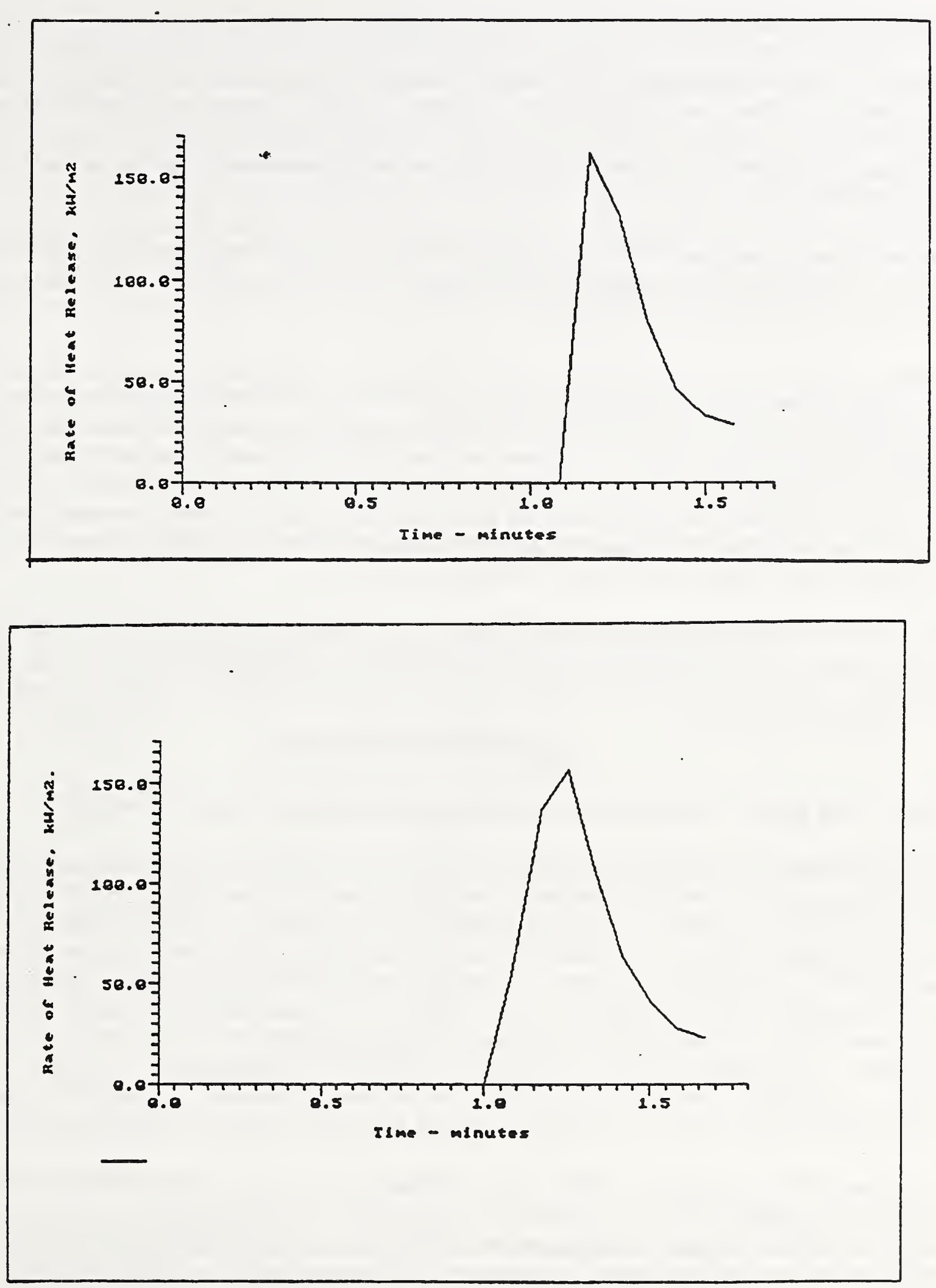

Figure 3. The $\mathrm{rhr}$ curves at $40 \mathrm{~kW} / \mathrm{m}^{2}$ for an untreated honeycomb composite and for a sample of the same material after it had absorbed a dose of $1.0 \mathrm{MGy}$. 


\section{E. Measurement Techniques}

The NIST Cone Calorimeter was used to make all flammability measurements. This instrument measures a number of combustion-related properties including rhr and is the basis for an ASTM test method (E1354-90a) [8]. Samples ( $50 \mathrm{~g}$ ) were placed in a pyrex dish and exposed to a specified heat flux radiating from an external source. A high voltage arc was placed between the source and the sample to ignite the off-gases.

Thermogravimetric analyses (TGA) were performed in $\mathrm{N}_{2}$ using a Perkin-Elmer 7 Series Thermal Analysis System. The samples, which weighed approximately $1 \mathrm{mg}$ at the onset of the experiments, were heated from 30 to $800^{\circ} \mathrm{C}$ at a rate of $10^{\circ} \mathrm{C} / \mathrm{min}$.

Infrared analyses of the evolved gases (FTIR-EGA) were performed using a gas cell with a $10 \mathrm{~cm}$ pathlength and programmable pyrolyzer manufactured by Chemical Data Systems Instruments. Samples, ranging from about $10-20 \mathrm{mg}$ in mass, were placed in a quartz tube which was surrounded by a resistance heating element. This assembly was inserted into the IR cell which was purged with $\mathrm{N}_{2}$ and heated either isothermally at a series of temperatures between 800 and $850{ }^{\circ} \mathrm{C}$ or dynamically from 25 to $1000{ }^{\circ} \mathrm{C}$ at a rate of $50{ }^{\circ} \mathrm{C} / \mathrm{min}$. The progress of the pyrolysis was monitored every 5 seconds for the kinetics measurements and every 20 seconds in the dynamic heating experiments. The spectra were collected on a Mattson Galaxy 7000 Series FTIR at a resolution of $2 \mathrm{~cm}^{-1}$.

The ${ }^{13} \mathrm{C}$ nuclear magnetc resonance (NMR) spectra were measured using the cross polarization (CP)/magic angle spinning (MAS) technique [9] at $25.193 \mathrm{MHz}$ in a static field of $2.354 \mathrm{~T}$. The spectra were acquired at a spinning rate of $4 \mathrm{kHz}$ with contact and repetition times of $1 \mathrm{~ms}$ and $3 \mathrm{~s}$, respectively.

\section{RESULTS AND DISCUSSION}

\section{Phase I. The Effect of Electron Beam Irradiation and Grafting on Polymer Flammability}

The flammability of crosslinked polyethylene (PE) was examined in previous investigations conducted in this laboratory [1,5]. Crosslinks were introduced by exposing the linear polymer to $1 \mathrm{Mev}$ electrons from a Van der Graaf accelerator. The times to ignition were measured as a function of absorbed dose on the Cone Calorimeter. The curves obtained for samples exposed to external radiative heat fluxes of 22,25 and $30 \mathrm{~kW} / \mathrm{m}^{2}$ are displayed in Figure 1. These data indicate that the most highly crosslinked polymers (i.e., the polymers with the highest absorbed doses) are the most difficult to ignite. Charring was a significant factor in prolonging ignition. The most highly crosslinked samples developed a char which appeared to obstruct the outward flow of gases, as evinced by the formation of bubbles on the polymer surface. Presumably, this lead to a reduction in the rate of emission of combustible gases and a concomitant increase in the time required to attain a flammable mixture in the air above the polymer.

The behavior of the polymers while they were burning was even more striking. Under normal circumstances, linear PE will not char when it is burned. The crosslinked PE, however, left a measurable amount of char; on the order of a few percent at $20 \mathrm{~kW} / \mathrm{m}^{2}$. Indeed, glowing combustion, as indicated by the formation of red-hot embers, was observed for the most highly crosslinked polymers.

The favorable results obtained in the case of PE prompted an investigation into the effect of high energy electrons on the flammability of honeycomb composite material. The rhr and ignition times were measured as functions of absorbed dose on the Cone Calorimeter for incident flux values ranging from 
30 to $60 \mathrm{~kW} / \mathrm{m}^{2}$. The critical flux of the unexposed composite, defined as the minimum value required for ignition, was determined to be $34.4 \pm 0.6 \mathrm{~kW} / \mathrm{m}^{2}$. The data summarized in Figures 2 and 3 , however, demonstrate that exposure to electron beam radiation does not have a measurable effect on either the ignition time or rhr of this material.

The behavior of crosslinked PE when it was burned also suggested that it may be possible to achieve a beneficial effect by grafting a fire resistant shell to the surface of an otherwise flammable material. Additional research was conducted to investigate this possibility. Samples of PS containing either PSAN or $(\mathrm{P}(\mathrm{AN}-\mathrm{VDC})$ ) copolymers were prepared. The times to ignition and rhr values are presented in Table I. The presence of $\mathrm{P}(\mathrm{AN}-\mathrm{VDC})$ does have a favorable effect in reducing the flammability of PS. The $\mathrm{P}(\mathrm{AN}-\mathrm{VDC}) / \mathrm{PS}$ composites have lower peak rhr values and longer times to ignition than the pure PS samples.

The results obtained for the PSAN/PS samples are more difficult to interpret because of variation in the flammability properties of the PSAN copolymer itself. The PSAN which was obtained from a commercial vendor took longer to ignite, but had a slightly higher peak rhr than the PS. In contrast, the ignition time for the laboratory synthesized PSAN was much shorter and the peak rhr significantly less. Residual solvent from the synthesis may have been responsible for reducing the time to ignition. In either case, the flammability of the composite materials seemed to be determined by the properties of the surface layer.

\begin{tabular}{|ccc||}
\hline \multicolumn{3}{|c||}{ Fable I. } \\
\hline Sample & Time to Ignition (s) & Peak RHR $\left(\mathrm{kW} / \mathrm{m}^{2}\right)$ \\
PS & External Flux $=20 \mathrm{~kW} / \mathrm{m}^{2}$ & \\
PSAN (commercial) & 282 & 595 \\
PSAN (synthesized) & 412 & 630 \\
PSAN/PS (layered) & 191 & 471 \\
PSAN/PS (grafted) & 471 & 633 \\
& 239 & 509 \\
PS & 151 & 471 \\
P(AN-VDC) & $>600$ & 0 \\
P(AN-VDC)/PS (layered) & 600 & 196 \\
P(AN-VDC)/PS (precipitated) & 72 & 190 \\
\hline \hline
\end{tabular}

a. Sample did not ignite 
Phase II. Reducing the Flammability of Honeycomb Composite Material

\section{A. Honeycomb Composites}

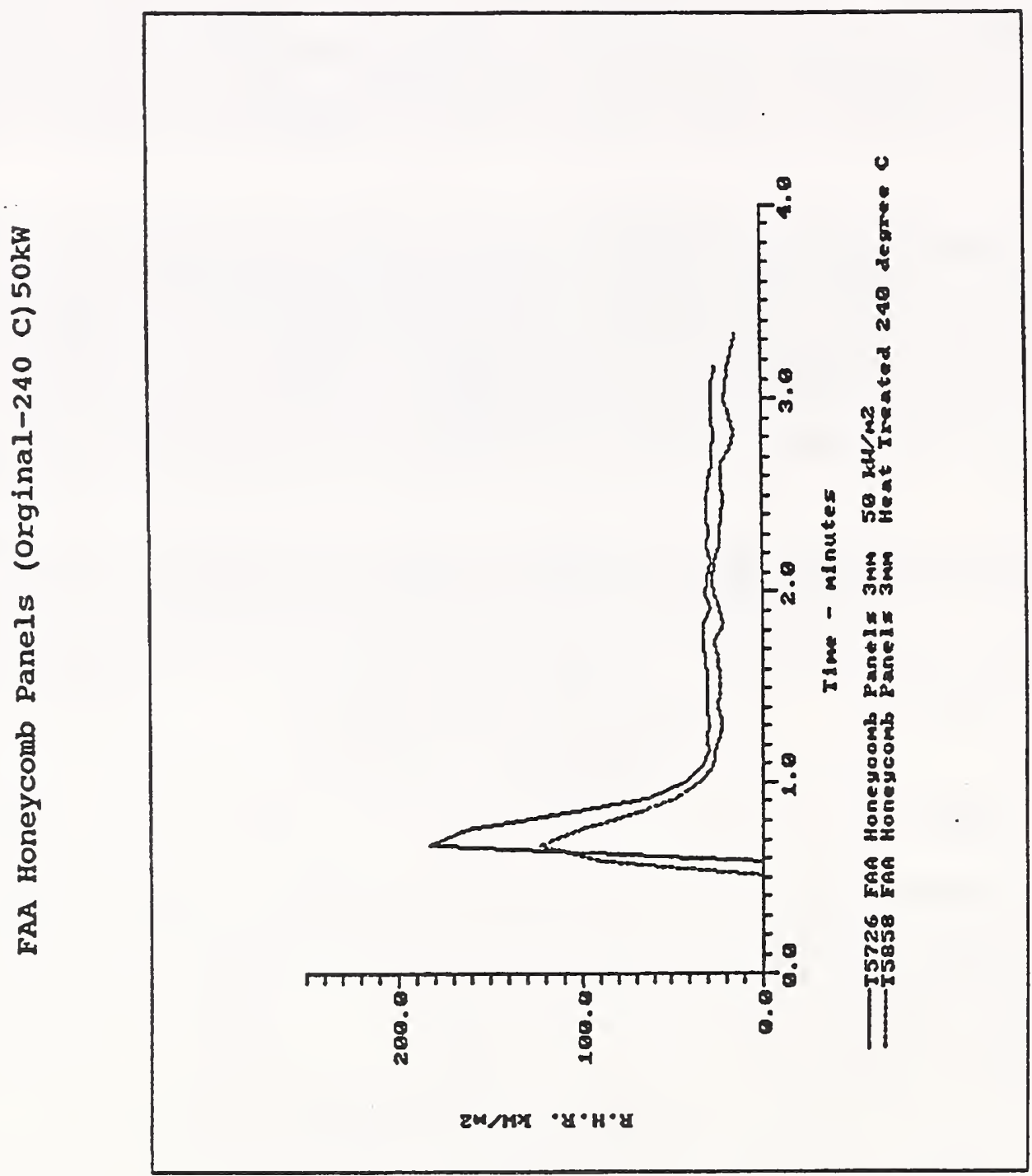

Figure 4. Comparison of $\mathrm{rhr}$ curves obtained by burning honeycomb composite material before (upper) and after the heat treatment.

The rhr from a sample of honeycomb composite exposed to an incident flux of $50 \mathrm{~kW} / \mathrm{m}^{2}$ is displayed as a function of burn time in Figure 4 (upper curve). Initially, these composites burn with a yellow luminous flame indicative of the presence of soot. This appears as a distinct peak in the rhr curve centered at about 45 seconds. The luminosity disappears about 15 seconds later, giving way to an unstable blue flame which is associated with fluorescent emissions accompanying the oxidation of $\mathrm{CO}$. 
The composites usually continue to smolder long after the flame disappears. This effect is indicated by the tail in the rhr curve which extends from about 70 seconds.

The lower curve in Figure 4 is the rhr from a sample taken from the same panel which was heated in an oven overnight at $250{ }^{\circ} \mathrm{C}$ before it was burned. At this external flux $\left(50 \mathrm{~kW} / \mathrm{m}^{2}\right)$ the peak rhr of the treated composite was about $30 \%$ lower than the value obtained for the untreated composite. The effect of the heat treatment was even more pronounced when the samples were exposed to less radiant energy. At a flux of $40 \mathrm{~kW} / \mathrm{m}^{2}$, for example, a $50 \%$ reduction in the peak $\mathrm{rhr}$ was observed after the heat treatment.

The thermograms of composite material taken before (Figure 5) and after (Figure 6) the heat treatment exhibit differences in the region between 500 and $575^{\circ} \mathrm{C}$. A comparison of the corresponding FTIR-EGA spectra is even more revealing (Figure 7). The peaks centered at about 1300 and $3000 \mathrm{~cm}^{-1}$, which are most prominent in the spectrum of the untreated composite, are due to $\mathrm{CH}_{4}$. The FTIR-EGA spectra obtained from the components of treated (Figure 8) and untreated (Figure 9) composites indicate that much higher levels of $\mathrm{CH}_{4}$ are generated from the degradation of the resin than from the fiber backing or honeycomb. Thus, there is a correlation between the amount of $\mathrm{CH}_{4}$ produced in the thermal degradation of the resin and the rhr of the composite. Based on this observation, it is clear that any effort directed at improving the fire resistance of the honeycomb composite material used in the interior cabin compartments of commercial aircraft should encompass a study of the flammability properties of phenolformaldehyde resins.

\section{B. Synthetic Resins}

The base catalyzed reaction of phenol with formaldehyde produces stable hydroxymethylphenol intermediates which condense into branched polymers (resoles) at temperatures of between 60 and 100 ${ }^{\circ} \mathrm{C}[10]$. Further condensation of methylol groups occur during the curing process resulting in the formation of highly crosslinked network polymers. Methylene bridges, which are produced in head-to-tail interactions between methylphenols, predom in ate over ether linkages [11] which form when methylphenols are aligned in a head-to-head configuration or from condensation of methylphenols with phenol.

A thorough investigation of the degradation properties of PF resins was conducted by Conley and coworkers [11-14]. They concluded that the primary degradation pathway for PF resins is oxidative in nature even in an oxygen deficient atmosphere and that thermal processes only begin to compete at higher temperatures. The spectra obtained in dynamic FTIR-EGA experiments indicate that $\mathrm{H}_{2} \mathrm{O}, \mathrm{CO}_{2}$ and $\mathrm{CH}_{3} \mathrm{OH}$ are evolved in the degradation of $\mathrm{PF}$ resins in $\mathrm{N}_{2}$ at temperatures as low as $250{ }^{\circ} \mathrm{C}$ (Figure 10). The presence of $\mathrm{CO}$ is first detected at about $350{ }^{\circ} \mathrm{C}$, while $\mathrm{CH}_{4}$, which is a major product of the thermal degradation of the resin, is evident only at temperatures above $550{ }^{\circ} \mathrm{C}$.

Rate constants $(\mathrm{k})$ for the formation of $\mathrm{CO}_{2}$ and $\mathrm{CH}_{4}$ are reported in Table II. The values were determined from

$$
\ln \left(1-\frac{[\alpha]_{t}}{[\alpha]_{\infty}}\right)=-k t,
$$

where $[\alpha]_{t}$ denotes the integrated absorbance of either product at time $t$ and $[\alpha]_{\infty}$ is the asymtoptic value which is attained in the limit as $\mathrm{t} \rightarrow \infty$. The global activation energies for $\mathrm{CO}_{2}$ and $\mathrm{CH}_{4}$, based on rate constants measured under isothermal conditions for temperatures between 800 and $850^{\circ} \mathrm{C}$, are $59 \pm 13$ 


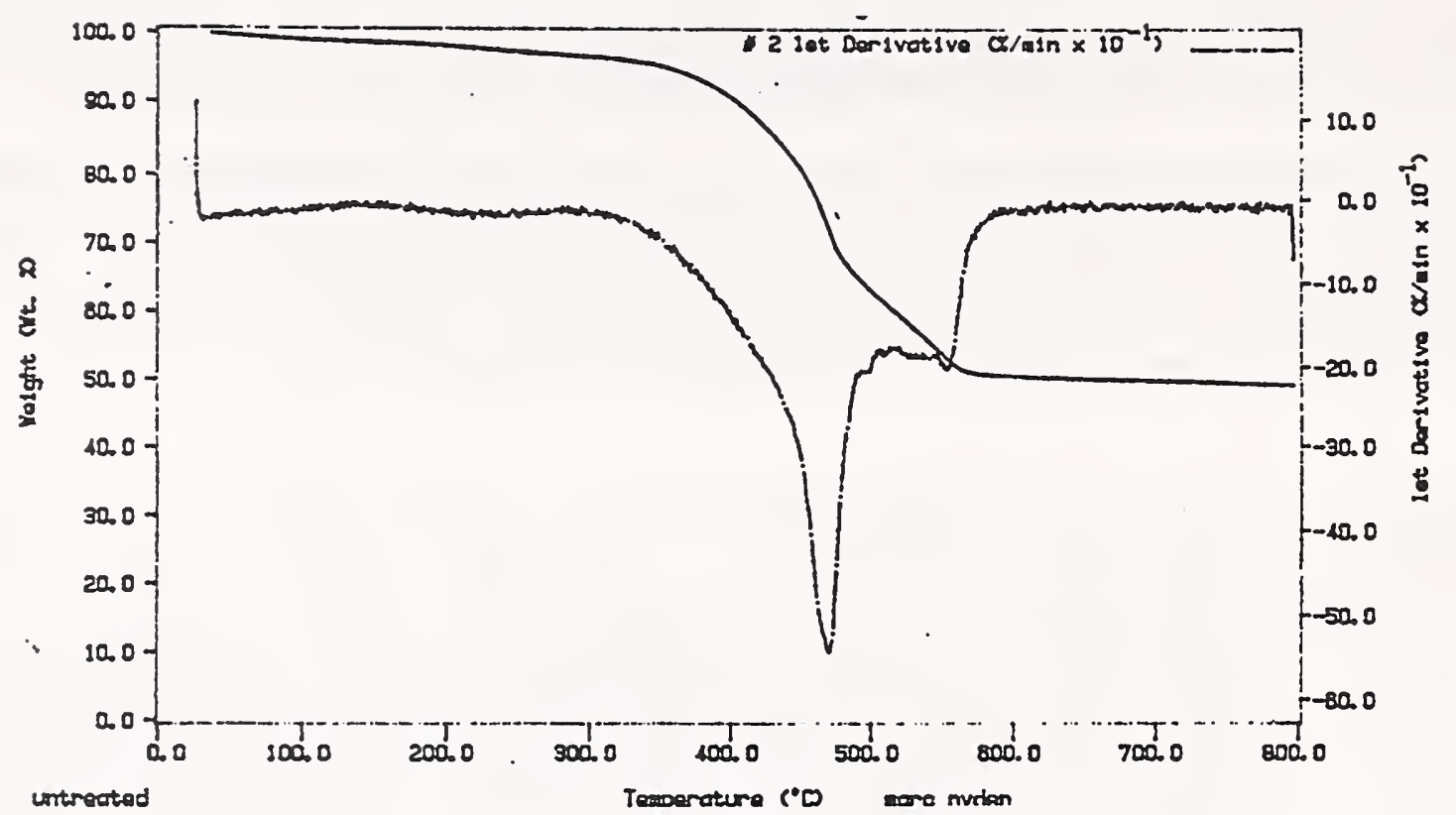

Figure 5. Thermograms of resin taken from an untreated panel.

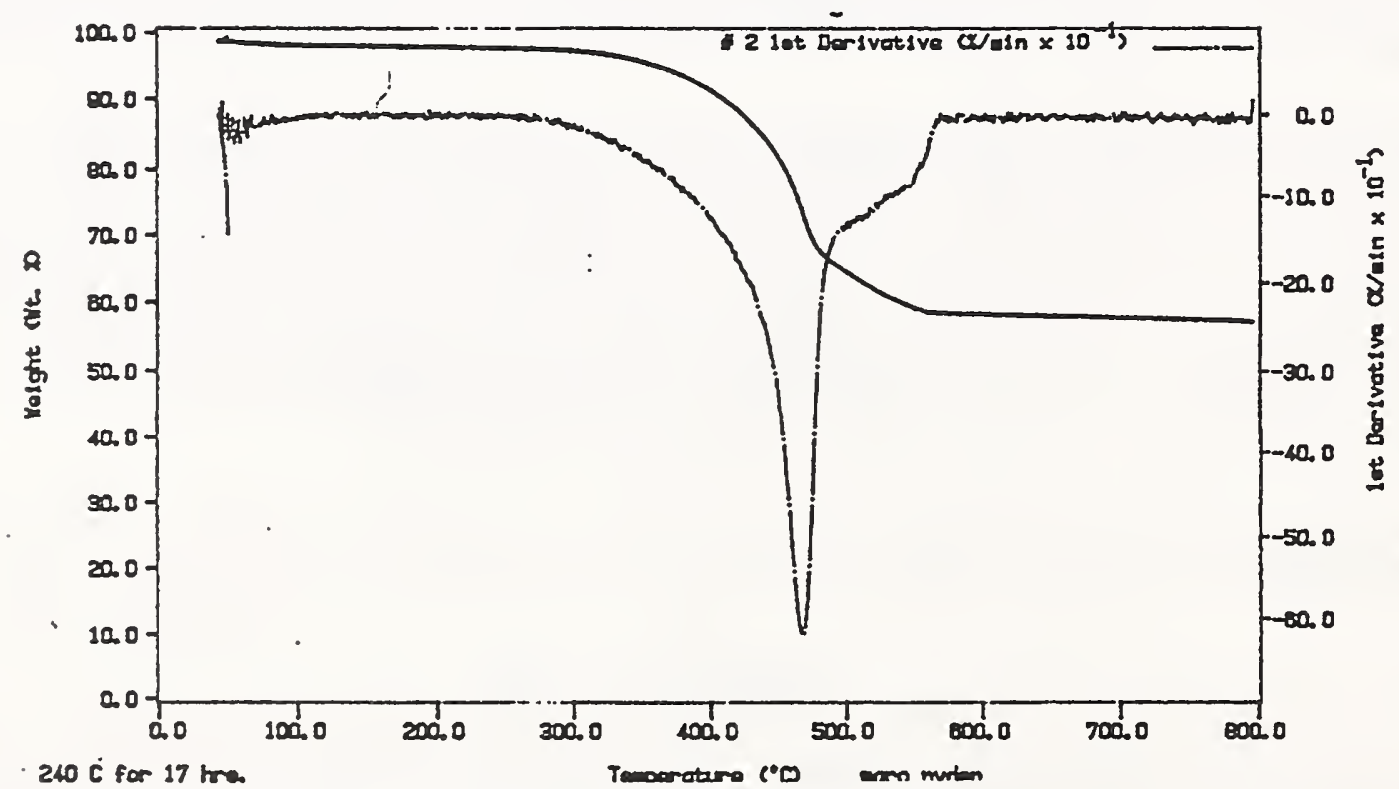

Figure 6. Thermograms of resin taken from a heat treated pane. 


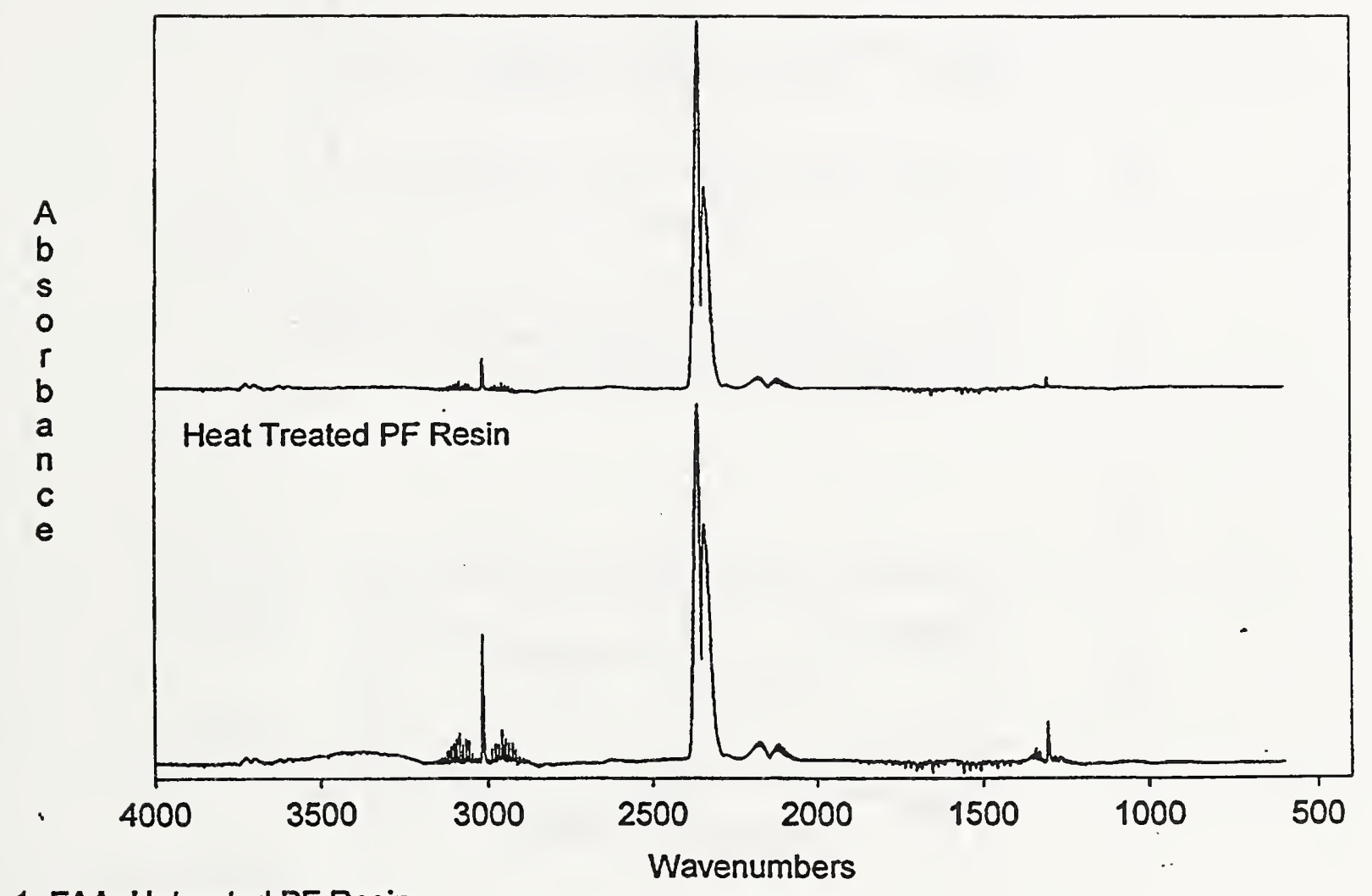

1: FAA: Untreated PF Resin

2: FAAT: Heat Treated PF Resin

Figure 7. Comparison of FTIR-EGA spectra of resins taken from untreated (lower) and heat treated panels. 


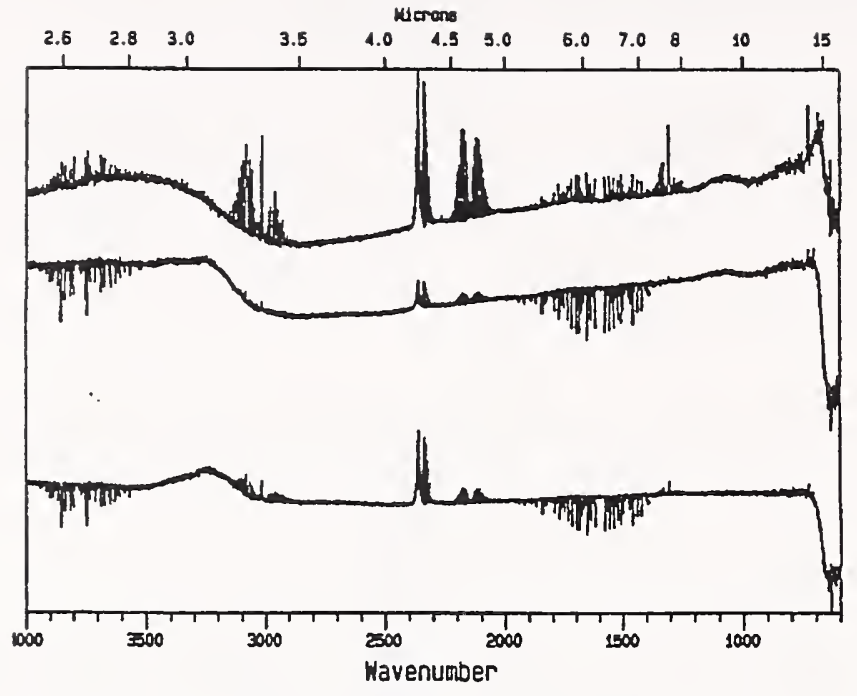

Figure 8. FTIR-EGA absorbance spectra $\left(1000^{\circ} \mathrm{C}\right)$ of the honeycomb (lower), fiber backing, and resin (upper) taken from an untreated panel.

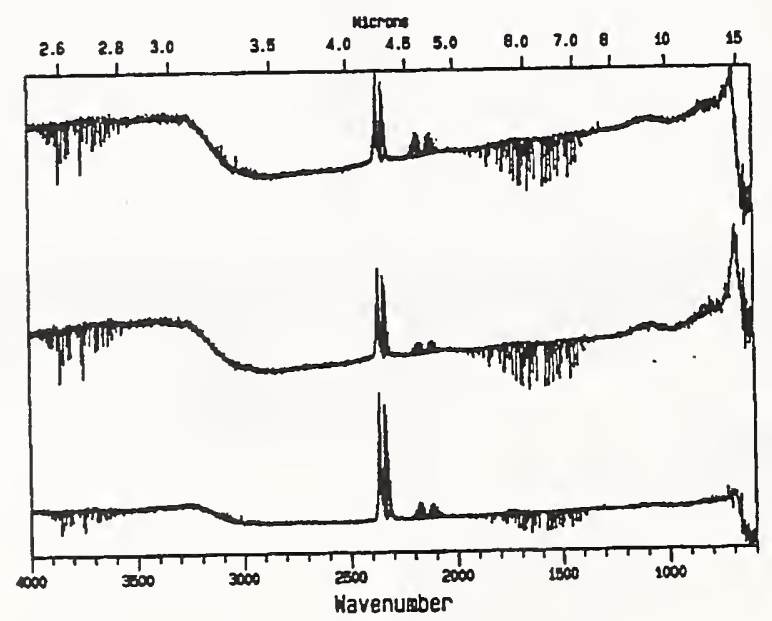

Figure 9. FTIR-EGA absorbance spectra $\left(1000^{\circ} \mathrm{C}\right)$ of the honeycomb (lower), fiber backing, and resin (upper) taken from a heat treated panel. 


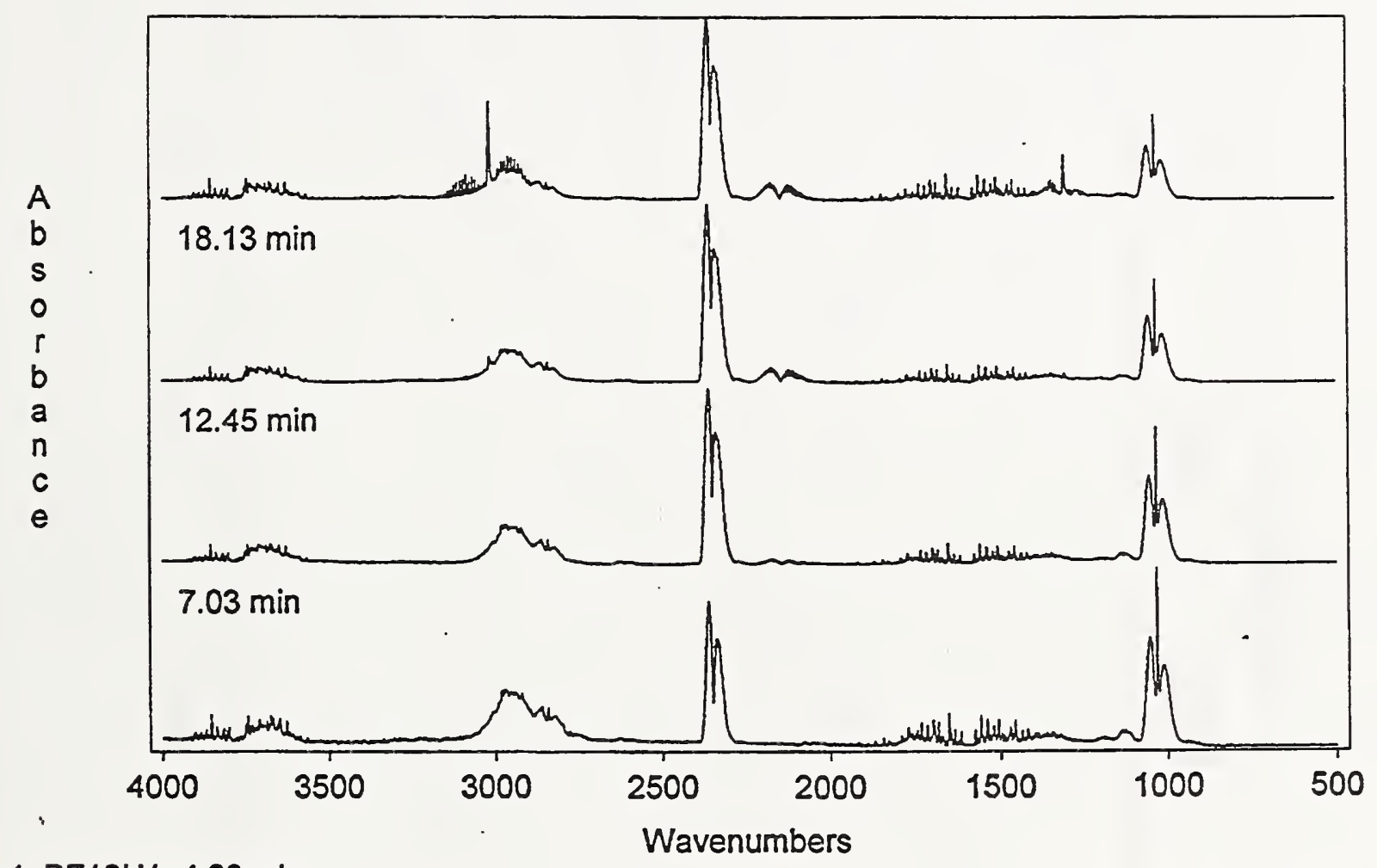

1: PF12U1: $4.60 \mathrm{~min}$

2: PF12U2: $7.03 \mathrm{~min}$

3: PF12U3: $12.45 \mathrm{~min}$

Figure 10. FTIR-EGA spectra of PF resin at 250 (bottom), 375,650 and $930^{\circ} \mathrm{C}$ (top). 


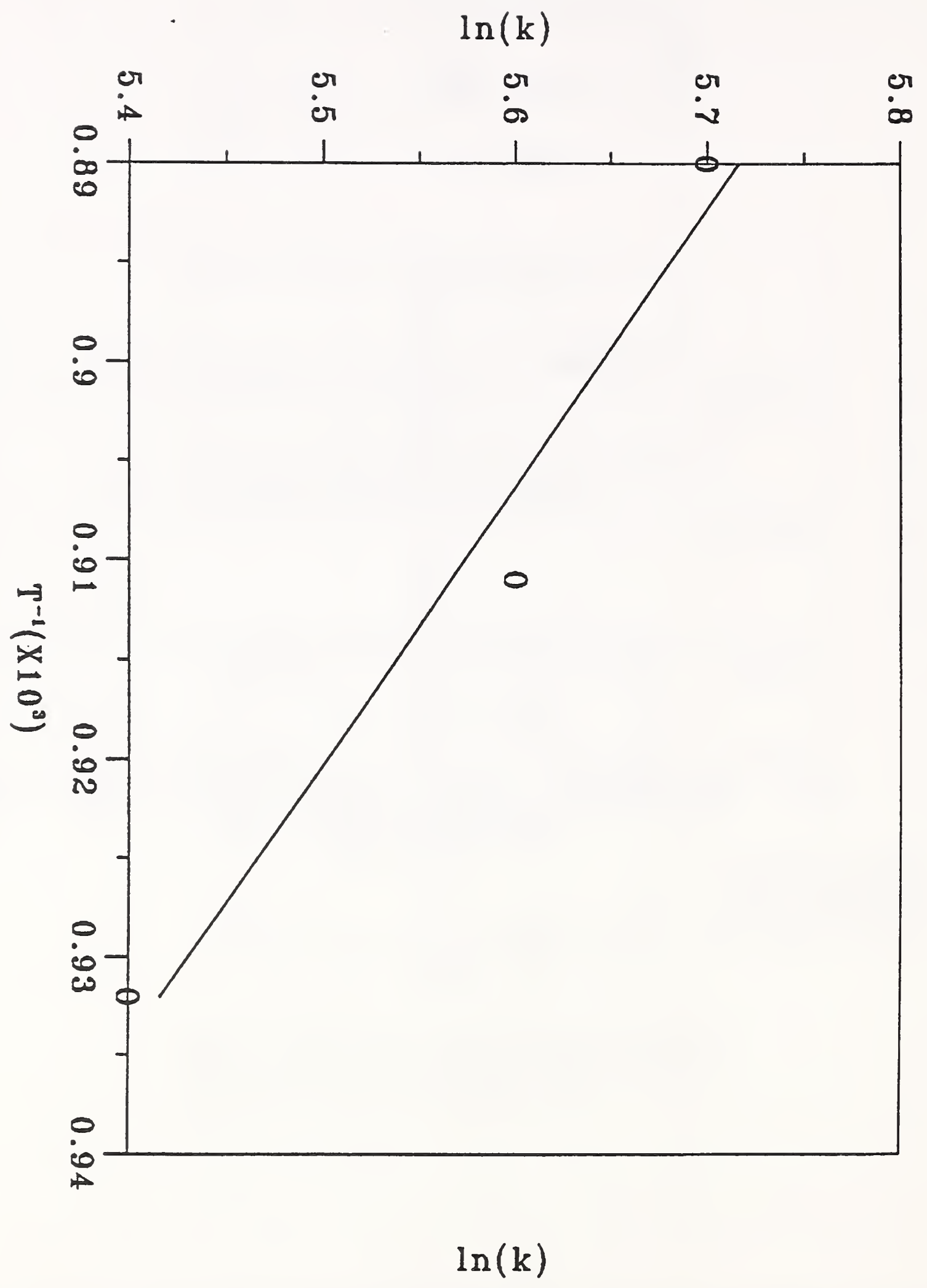

Figure 11. Plot of $\ln (\mathrm{k})$ vs $\mathrm{T}^{-1}$ for the formation of $\mathrm{CO}_{2}$. 


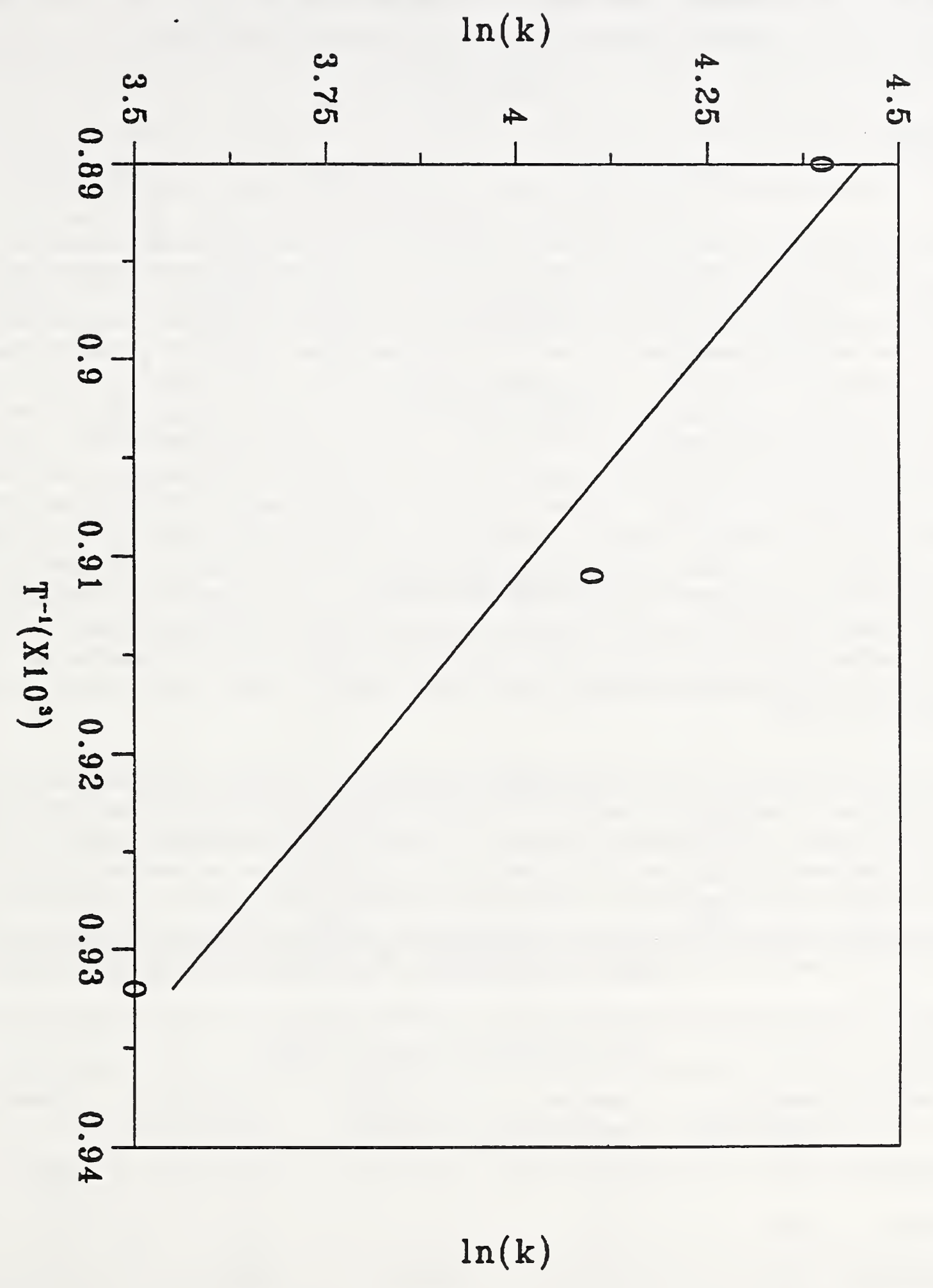

Figure 12. Plot of $\ln (k)$ vs $\mathrm{T}^{-1}$ for the formation of $\mathrm{CH}_{4}$. 
$\mathrm{kJ} / \mathrm{mol}$ and $180 \pm 33 \mathrm{~kJ} / \mathrm{mol}$, respectively (Figures 11 and 12).

\begin{tabular}{|c|c|c|c|}
\hline Table II. & \multicolumn{3}{|c|}{ Rate Constants $\left(\mathrm{s}^{-1}\right)$ for the Formation of $\mathrm{CO}_{2}$ and $\mathrm{CH}_{4}$} \\
\hline \multicolumn{4}{|c|}{ Temperature $\left({ }^{\circ} \mathrm{C}\right)$} \\
\hline Compound & 800 & 825 & 850 \\
\hline $\mathrm{CO}_{2}$ & $0.090 \pm 0.005$ & $0.093 \pm 0.030$ & $0.095 \pm 0.012$ \\
\hline $\mathrm{CH}_{4}$ & $0.058 \pm 0.003$ & $0.068 \pm 0.003$ & $0.073 \pm 0.008$ \\
\hline
\end{tabular}

A mechanism has been advanced for the formation of $\mathrm{CO}$ and $\mathrm{CO}_{2}$ during the oxidative degradation of $\mathrm{PF}$ resins. According to Conley [11], the first step is the conversion of methylene bridges into carbonyl linkages. The resulting benzophenones can either undergo thermal scission to produce $\mathrm{CO}$ or further oxidation resulting in the formation of benzoates which then release $\mathrm{CO}_{2}$ in decarboxylation reactions. The evidence for this mechanism is compelling, however, the extension to oxygen deficient atmospheres, which will be the prevailing condition at the surface of a burning polymer, is questionable. The postulate that the $\mathrm{CH}_{4}$ comes from the thermal scission of methylene bridges is also suspect since this bond is known to be exceptionally strong. The bond dissociation enthalpy, based on the difference between the measured heats of formation of diphenylmethane (Figure 13) [15] and the benzyl [16] and phenyl [17] radicals, is $389 \mathrm{~kJ} / \mathrm{mol}$. In fact, a simple mechanism whereby the methylphenol condensation process is reversed at elevated temperatures in the presence of residual $\mathrm{H}_{2} \mathrm{O}$ can account for the evolution of all of the major volatile products. The $\mathrm{CH}_{2} \mathrm{O}$, which is released during the depolymerization of the resin, is known to produce $\mathrm{CH}_{3} \mathrm{OH}$ and $\mathrm{CO}_{2}$ via the Cannizarro reaction, while the formation of $\mathrm{CH}_{4}$ from rearrangement of hemiacetal intermediates also seems likely; at least at the elevated temperatures considered in this study.

As is the case with many polymers, the flammability properties of PF resins will depend on how they are prepared and cured. The range of possibilities was explored by comparing the flammability performance of cured and uncured resins synthesized from reaction mixtures containing different proportions of the two monomers. The results of the Cone Calorimeter measurements taken at an external flux of $50 \mathrm{~kW} / \mathrm{m}^{2}$ (Table III) indicate that flammability increases with increasing mole fraction of formaldehyde in the reaction mixture and that the cured resins are significantly less flammable than the uncured resins. The high levels of char and low heat release rates exhibited by the 2:1 resins are remarkable, considering the

\begin{tabular}{||llllll||}
\hline \hline Table III. & \multicolumn{5}{c||}{ Flammability Properties of PF Resins } \\
\hline Moles of P:F & $\begin{array}{l}\text { Mass of } \\
\text { Sample }(\mathrm{g})\end{array}$ & $\begin{array}{l}\text { Time to } \\
\text { Ignition }(\mathrm{s})\end{array}$ & $\begin{array}{c}\text { Peak RHR } \\
\left(\mathrm{kW} / \mathrm{m}^{2}\right)\end{array}$ & $\begin{array}{l}\text { Total Heat } \\
\left(\mathrm{MJ} / \mathrm{m}^{2}\right)\end{array}$ & Residue (\%) \\
$1: 2$ (uncured) & 45.2 & 124 & 213 & 113 & 49.8 \\
$1: 2$ (cured) & 66.3 & 102 & 174 & 23 & 76.6 \\
$1: 1$ (uncured) & 42.2 & 422 & 164 & 148 & 44.8 \\
$2: 1$ (uncured) & 45.0 & 44 & 116 & 10 & 93.9 \\
$2: 1$ (cured) & 66.3 & 59 & 79 & 5 & 95.1 \\
\hline
\end{tabular}


high flux of incident radiation used in these tests. The relative amounts of $\mathrm{CO}_{2}, \mathrm{CH}_{3} \mathrm{OH}$ and $\mathrm{CH}_{4}$ produced in the thermal degradation of the resins in $\mathrm{N}_{2}$ were estimated from characteristic peaks in the steady-state FTIR-EGA spectra measured at $800{ }^{\circ} \mathrm{C}$. The values obtained by dividing the integrated absorbance of the characteristic peak by the initial mass of the sample are listed in Table IV. The $\mathrm{CH}_{3} \mathrm{OH}$ data follow the same trends observed in the flammability performance of the resins. This is not true in the case of $\mathrm{CO}_{2}$, however, which appears at higher levels in the less flammable cured resins. There is some indication that the evolution of $\mathrm{CH}_{4}$ may follow a similar trend. Unfortunately, the uncertainty in these measurements is too large to make a definitive statement. The variations between different samples of the same resin, which approached $50 \%$ of the measured values, were of the same order of magnitude as were the variations between the samples taken from different resins.

\begin{tabular}{|c|c|c|}
\hline Table IV. & \multicolumn{2}{|c|}{ Integrated Peak Absorbance at $800^{\circ} \mathrm{C}$} \\
\hline Moles of P:F & Uncured & Cured \\
\hline \multicolumn{3}{|c|}{$\mathrm{CH}_{4}\left(1295-1310 \mathrm{~cm}^{-1}\right)$} \\
\hline $1: 2$ & 14 & 29 \\
\hline $1: 1$ & 26 & 27 \\
\hline $2: 1$ & 14 & 20 \\
\hline \multicolumn{3}{|c|}{$\mathrm{CH}_{3} \mathrm{OH}\left(970-1085 \mathrm{~cm}^{-1}\right)$} \\
\hline $1: 2$ & 373 & 149 \\
\hline $1: 1$ & 157 & 44 \\
\hline $2: 1$ & 71 & 12 \\
\hline \multicolumn{3}{|c|}{$\mathrm{CO}_{2}\left(2285-2390 \mathrm{~cm}^{-1}\right)$} \\
\hline $1: 2$ & 1278 & 2143 \\
\hline $1: 1$ & 1053 & 1489 \\
\hline $2: 1$ & 232 & 326 \\
\hline
\end{tabular}

* Values normalized by dividing by the initial mass of the sample.

The ${ }^{13} \mathrm{C}$ CP/MAS spectra of the cured resins are displayed in Figure (14). The peak assignments, which were made using a computer program [18], were consistent with previously published data on phenolformaldehyde resins $[19,20]$. The integrated intensity of each peak, which is proportional to the number of carbon atoms corresponding to the specified assignment, is listed in Table V. Not all of the peaks were well resolved. In some cases, the contribution of the components had to be estimated by inspection. These values are indicated by an asterisks.

These spectra indicate structural differences between the resins which are consistent with the Cone Calorimeter data. In particular, the ratio of aromatic to aliphatic carbons is highest in the least flammable (2:1) resin. The two weak resonances centered at about 57 and $75 \mathrm{ppm}$, which are discernible in the spectra of both the 1:2 and the 1:1 resins, are indicative of the presence of aliphatic OH. This is a likely source of the $\mathrm{CH}_{3} \mathrm{OH}$ which was detected during pyrolysis of these resins. Indeed, the 2:1 resin also 
appears to contain significantly less aromatic $\mathrm{OH}$ as evinced by a reduction in the intensity of the resonance due to phenolic $\mathrm{OH}$ at $152 \mathrm{ppm}$. This oxygen is accounted for in the spectrum of the 2:1 resin by the broad resonance extending from about $155-180 \mathrm{ppm}$ which is characteristic of the presence of biphenyl ethers [19]. Presumably, these ether linkages are formed as a result of self-condensation of the phenol. Thus, it is not surprising that they are more prevalent in those resins which were synthesized in an excess of this reactant. Likewise, resins synthesized in excess formaldehyde might be expected to contain significant amounts of the formaldehyde homopolymer. Pure polyoxymethylene is known to be thermally labile. Depolymerization is thought to be initiated at the chain ends at about $200{ }^{\circ} \mathrm{C}[21]$ which

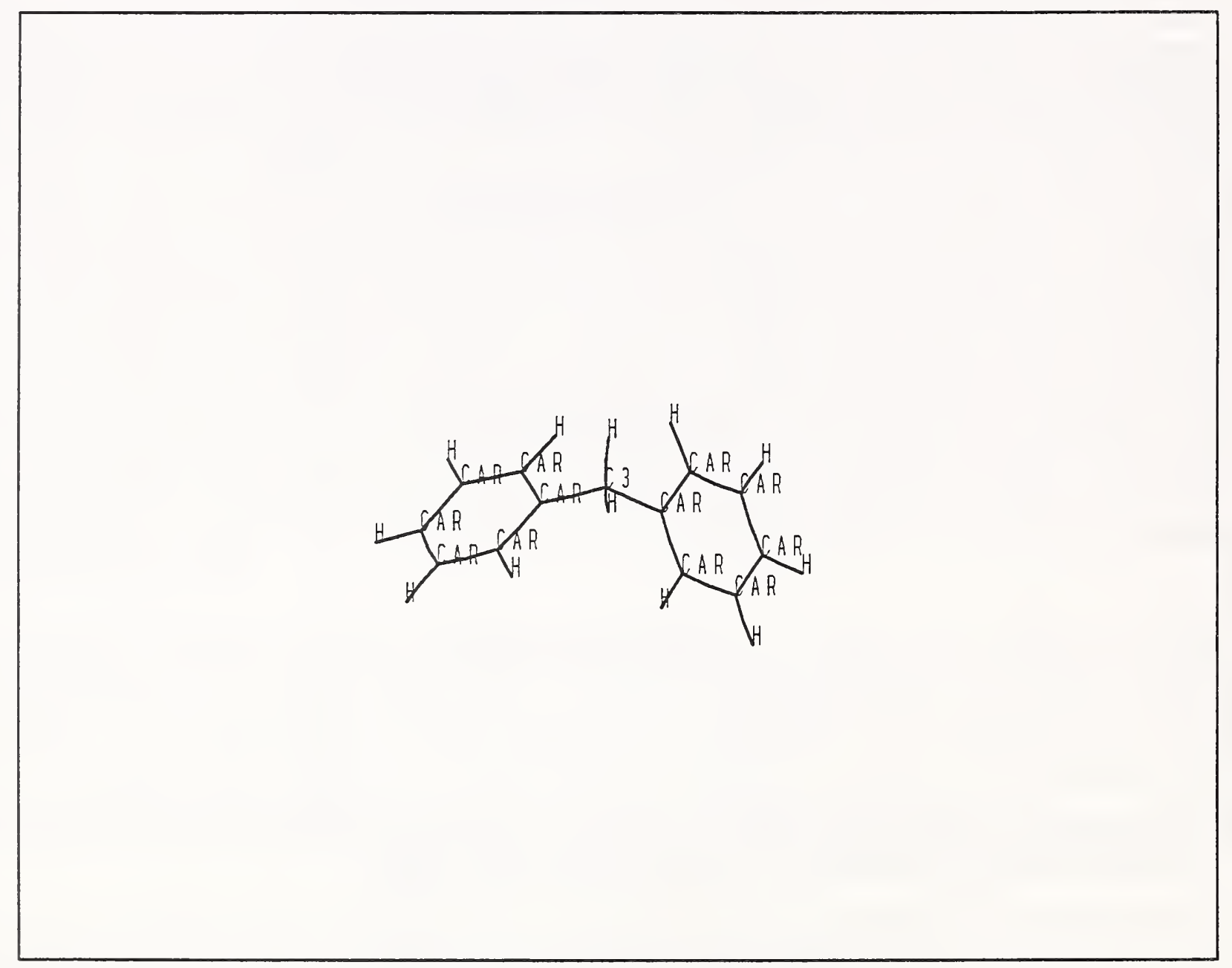

Figure 13. Diphenylmethane.

is consistent with the temperature at which $\mathrm{CH}_{3} \mathrm{OH}$ and $\mathrm{CO}_{2}$ first appear. The presence of polyoxymethylene in the $1: 1$ and 1:2 resins would account for the high levels of $\mathrm{CO}_{2}$ which are evolved during curing; even when this process is carried out in $\mathrm{N}_{2}$, as well as, providing a simple explanation for the reduced flammability of the cured resins. 


\section{CP/MAS 13C NMR (25MHz)}

M. Nyden phenolic resins, $72 \mathrm{~h}$ CURE

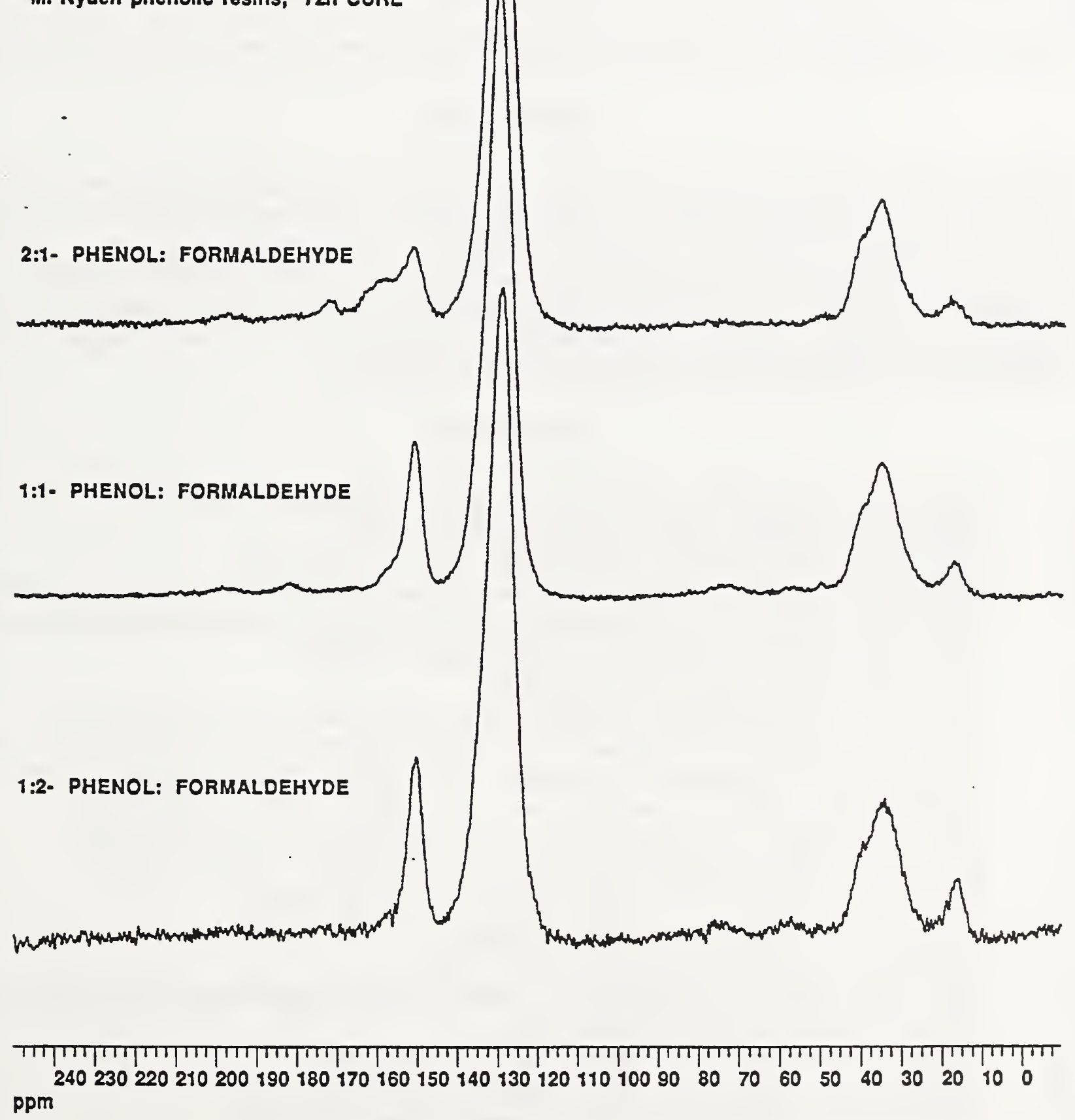

Figure 14. ${ }^{13} \mathrm{C}$ CP/MAS NMR spectra of the 1:2 (bottom), 1:1 (middle) and 2:1 PF resins(top). 


\begin{tabular}{||ccccccc||}
\hline Table V. & \multicolumn{7}{c||}{${ }^{13} \mathrm{C}$ NMR Integrated Peak Intensities } \\
\hline $\begin{array}{c}\text { Assignment/ } \\
\text { P:F Ratio }\end{array}$ & $\mathrm{C}(\mathrm{ar})-\mathrm{O}-\mathrm{C}(\mathrm{ar})$ & $\mathrm{C}(\mathrm{ar})-\mathrm{OH}$ & $\mathrm{C}(\mathrm{ar})$ & $-\mathrm{OCH}_{2}$ & $\mathrm{CH}_{3}$ & ar:al \\
& $160-180 \mathrm{ppm}$ & $152 \mathrm{ppm}$ & $130 \mathrm{ppm}$ & $55-80 \mathrm{ppm}$ & $15 \mathrm{ppm}$ & Ratio \\
$1: 2$ & 3.0 & 11.2 & 60.5 & 4.1 & 4.3 & 3.0 \\
$1: 1$ & $2.3^{\circ}$ & $9.1^{*}$ & 61.6 & 3.0 & 2.4 & 3.1 \\
$2: 1$ & $8.7^{*}$ & $8.7^{*}$ & 58.8 & 0.0 & 2.6 & 3.4 \\
\hline
\end{tabular}

\section{CONCLUSIONS}

The flammability of the honeycomb composite material considered in this investigation was not affected by exposure to electron beam radiation. A dramatic reduction in the peak rhr, however, was observed when this material was heated in an oven overnight at a temperature of $250{ }^{\circ} \mathrm{C}$. FTIR-EGA measurements indicated that combustible products, particularly $\mathrm{CH}_{4}$ and $\mathrm{CH}_{3} \mathrm{OH}$ which are released during the thermal degradation of the PF resin, make a significant contribution to the flammability of these composites. A dramatic reduction in flammability was demonstrated in the case of resins which were synthesized from reaction mixtures containing an excess of phenol.

\section{REFERENCES}

1. Nyden, M.R., Forney, G.P. and Brown, J.E., Macromolecules 25, 1658 (1992).

2. Nyden, M.R. and Noid, D.W., Phys. Chem. 95, 940 (1991).

3. Barojas, E.B. and Nyden, M.R., Chem. Phys. Lett. 171, 499 (1990).

4. Lomakin, S.M., Brown, J.E., Breese, R.S. and Nyden, M.R., Pol. Deg. Stab. 41, 229 (1993).

5. Nyden, M.R. and Brown, J.E., Proceedings of the International Conference for the promotion of Advanced Fire Resistant Aircraft Interior Materials, 147 (1993).

6. van Krevelen, D.W., Polymer 16, 615 (1975).

7. Martin, R.W., The Chemistry of Phenolic Resins, John Wiley, New York, 298 (1956).

8. Standard Test Method for Heat and Visible Smoke Release Rates for Materials and Products Using an Oxygen Consumption Calorimeter, ASTM E-1354, Philadelphia, PA, 1 (1991).

9. VanderHart, D.L., Earl, W.L. and Garroway, A.N., J. Magn. Reson. 44, 361 (1981).

10. Knop, A. and Pilato, L.A., Phenolic Resins, Springer-Verlag, New York, 25 (1985).

11. Conley, R.T., Themal Stability of Polymers, John Wiley, New York, 457 (1970).

12. Conley, R.T. and Bieron, J.F., J. Appl. Polymer Sci. 7, 103 (1963).

13. Conley, R.T. and Bieron, J.F., J. Appl. Polymer Sci. 7, 171 (1963).

14. Conley, R.T.., J. Appl. Polymer Sci. 9, 1117 (1965).

15. Pedley, J.B., Naylor, R.D. and Kirby, S.P., Thermochemical Data of Organic Compounds, Second Edition, Chapm an and Hall, London (1986).

16. Walker, J.A. and Tsang, W., J. Phys. Chem 94, 3324 (1990).

17. Robaugh, D. and Tsang, W., J. Phys. Chem. 90, 5363 (1986).

18. ChemWindow3, SoftShell International, Grand Junction, CO (1994). 
19. Maciel, G.E., Chuang, I. and Gollob, L., Macromolecules 17, 1081 (1984).

20 Amram, B. and Laval, F., J. Appl. Polym. Sci. 37, 1 (1989).

21. Madorsky, S.L., Thermal Degradation of Organic Polymers, John Wiley, New York, 228 (1964).

\section{ACKNOWLEDGEMENTS}

The author would like to acknowledge assistance from the following people. Mr. Jack Lee (BFRL/NIST) made the Cone-Calorimeter flammability measurements, Dr. S.M. Lomakin (Russian Academy of Sciences) synthesized the phenol - formaldehyde resins, Dr. Barry Bauer (MSEL/ NIST) conducted the exploratory study of the flammability properties of polystyrene composites, and Dr. Jeffery Gilman (BFRL/NIST) performed the ${ }^{13} \mathrm{C}$ CP/MAS measurements. 


